\title{
Gastric Bypass and Absorption of Antihypertensive Medications
}

\author{
Ahmed E. Altyar, PharmD \\ Department of Clinical Pharmacy, Faculty of Pharmacy \\ King Abdulaziz University, Jeddah, Saudi Arabia
}

\section{Correspondence \\ Dr. Ahmed E. Altyar \\ P.O. Box 80260 \\ Jeddah 21589, Saudi Arabia \\ e-Mail: aealtyar@kau.edu.sa \\ Submission: 27 Feb 2018 \\ Accepted: 15 Mar 2018}

\section{Citation}

Altyar AE. Gastric bypass and absorption of antihypertensive medications. JKAU Med Sci 2018; 25 (1): 39-44. DOI: 10.4197/Med. 25.1.6

\begin{abstract}
Little is known about the effects of gastric bypass on the absorption of prescription medications in the post-operative state. This poses a considerable clinical dilemma especially that the prevalence of morbid obesity continues to escalate in the United States of America, and as a result the number of gastric bypass procedures performed each year has similarly increased dramatically. The author presented a case of a 45-year-old male with refractory hypertension, secondary to mechanical complications after a Roux-en-Y gastric bypass procedure due to anatomical alteration contributing to pill retention and change in medications' pharmacokinetics. Investigations for secondary causes of hypertension were made, patient's blood pressure had become exceedingly difficult to control after his Roux-en-Y gastric bypass procedure and had only been controlled with IV medications. Further investigations confirmed the diagnosis of a mechanical gastrointestinal complication.
\end{abstract}

\section{Keywords}

Roux-en-Y; Esophagogastroduodenoscopy; Malabsorption; Blood pressure; Jejunostomy

\section{Introduction}

0 besity is now a global epidemic, with more than one in five people considered as obese worldwide. This condition is usually accompanied by increased rates of non-communicable diseases related to obesity, like hypertension, and cardiovascular diseases. Saudi Arabia, which has become westernized over the past few years now has one of the highest prevalence rates of obesity, even among children. The recent data shows that around three fourths of females and nearly two third of males in Saudi Arabia are either overweight or obese $\mathrm{e}^{[1]}$.

In 2014, The International Federation for the Surgery of Obesity and Metabolic Disorders (IFSO) survey form evaluated the number and the type of surgical and endoluminal bariatric procedures worldwide. Trend analyses of the procedures were also performed from 2011-2014. The total number of bariatric/metabolic procedures done worldwide in 2014 were $579,517(97.6 \%)$ surgical operations and 14,725 (2.4\%) endoluminal procedures. The most frequently performed procedure around the world was sleeve gastrectomy (SG) which reached $45.9 \%$, followed by Roux-en-Y gastric bypass (RYGB) (39.6\%). In Saudi Arabia, 15,571 surgeries were performed of them, there were 3,033 RYGB while the sleeve gastrectomy reached 8,649 procedures $^{[2]}$.

Little is known about the effects of gastric bypass on the absorption of prescription medications in the post-operative state. This poses a considerable clinical 
dilemma as the number of patients undergoing gastric bypass currently exceeds 100,000 per year ${ }^{[3]}$. The author presented a case of refractory hypertension, secondary to mechanical complications after a RYGB procedure.

The surgically-modified anatomy which bypasses the lower stomach and a large part of the small intestine theoretically affects the bioavailability of oral medications due to changes in absorptive surface area, enzymatic activity, intestinal flora, solubility, intestinal transit time, and regional alterations in blood flow ${ }^{[4-7]}$.

\section{Case Report}

A 45-year-old male was referred to our medical facility by his nephrologist for evaluation of persistent accelerated hypertension. Patient's hypertension had been refractory to treatment with multiple complex oral anti-hypertensive regimens and had resulted in 19 separate admissions to medical facilities in the 2 years prior to admission. A past medical history of the patient was significant for original RYGB procedure 2 years prior to presentation, nephrolithiasis, stroke, and essential hypertension diagnosed 5 years earlier.

When interviewed in the clinic, the patient denied chest pain/pressure, palpitations, facial flushing, or changes in visual field or acuity. However, patient did endorse frequent frontally-located headaches described as "10/10 and throbbing", climaxing when his blood pressure was uncontrolled. Patient had no history of illegal drug use, was a lifetime non-smoker, and noted sparse alcohol use. Moreover, patient had no history of sleep apnea. His medication regimen at time of admission included: Amiloride $5 \mathrm{mg}$ twice daily, clonidine $0.3 \mathrm{mg}$ three times daily, hydralazine $100 \mathrm{mg}$ three times daily, hydrochlorothiazide $25 \mathrm{mg}$ once daily, labetalol $100 \mathrm{mg}$ four times daily, minoxidil $10 \mathrm{mg}$ twice daily and nifedipine extended release 90 mg once daily

Physical examination was remarkable for body mass index 37, blood pressure of $179 / 92 \mathrm{mmHg}$ in left arm, $181 / 89 \mathrm{mmHg}$ in right arm, with a pulse of 58. Cardiovascular examination disclosed subtle II/VI holosystolic murmur at the second right intercostal space, and hyperdynamic precordium. Patient also had residual left-sided lower extremity weakness from previous cerebrovascular accident. Fundoscopic exam did not disclose papilledema, however arteriovenous nicking was observed. The remainder of the physical examination was normal.
Routine blood work, including complete metabolic panel, complete blood count, liver function panel test, and urine toxicology screen were all within normal limits with the exception of a creatinine of $1.2 \mathrm{mg} /$ dl. Patient had a mildly elevated thyroid stimulating hormone (TSH) of $8.2(0.3-3.4 \mathrm{U} / \mathrm{ml})$ but normal free thyroxine $1.0(0.8-2.8 \mathrm{ng} / \mathrm{dl})$. Early morning cortisol level and insulin-like growth factor were normal and the patient's electrocardiogram was unremarkable.

Magnetic resonance angiography of the renal arteries and kidneys demonstrated widely patent renal arteries. Adrenal vein and inferior vena cava sampling of renin, aldosterone, epinephrine, and norepinephrine were all normal. Confirmatory plasma renin and aldosterone levels drawn one week later (while patient was off renin/angiotensin blocking agents) were both within normal limits as well. Patient had normal levels of urine metanephrine and normetanephrine. Moreover, testing for potential indolent auto-immune etiologies, including serum antinuclear antibody, antismooth muscle antibody, and scleroderma antibody were all negative.

\section{Discussion}

World Health Organization defines obesity as body mass index of $30 \mathrm{~kg} / \mathrm{m}$. Obesity is increasing ${ }^{[8]}$.

The prevalence of morbid obesity continues to escalate in Saudi Arabia, and as a result the number of gastric bypass procedures performed each year has similarly increased dramatically. There is a paucity of information detailing how bariatric surgery affects drug absorption and bioavailability. There are only a handful of case reports describing medication malabsorption in patients who have undergone RYGB procedures ${ }^{[9-12]}$.

Metoprolol and antihypertensive medications are known to pass the intestinal mucosa through passive diffusion. As this medication has a high solubility, its absorption is not normally to be changed significantly after RYGB procedures, which was confirmed in the many studies, regardless of the observed affinity towards a higher oral drug exposure. Besides its high solubility and high permeability, the absorption of antihypertensive medications by the gastrointestinal tract is fast and complete ${ }^{[13]}$.

With nearly all of the secondary causes of hypertension eliminated the patient's medical history 
was re-examined. Foremost, extensive review of patient's medical records, revealed that patient's blood pressure had become exceedingly difficult to control after his RYGB procedure. Moreover, during this and previous hospitalizations, patient's blood pressures had been controlled adequately with intravenous but not oral medications. Upon placement of nasogastric tube and reformulation of patient's medications to liquid preparations, patient's blood pressure was adequately controlled (Fig. 1). Suspecting a malabsorptive process, urine drug level testing was preformed following administration of hydrochlorothiazide tablets $12.5 \mathrm{mg}$ PO twice daily for five consecutive days. Urine drug levels were tested by using high performance liquid chromatography. A plasma level testing was also performed on two occasions following a 3-day administration of labetalol tablets (300 mg PO four times daily) and after a 7-day administration of labetalol $300 \mathrm{mg}$ three times daily oral suspension. Table 1 demonstrate that plasma levels were undetectable following assay on both occasions. These results are similar to the reduced

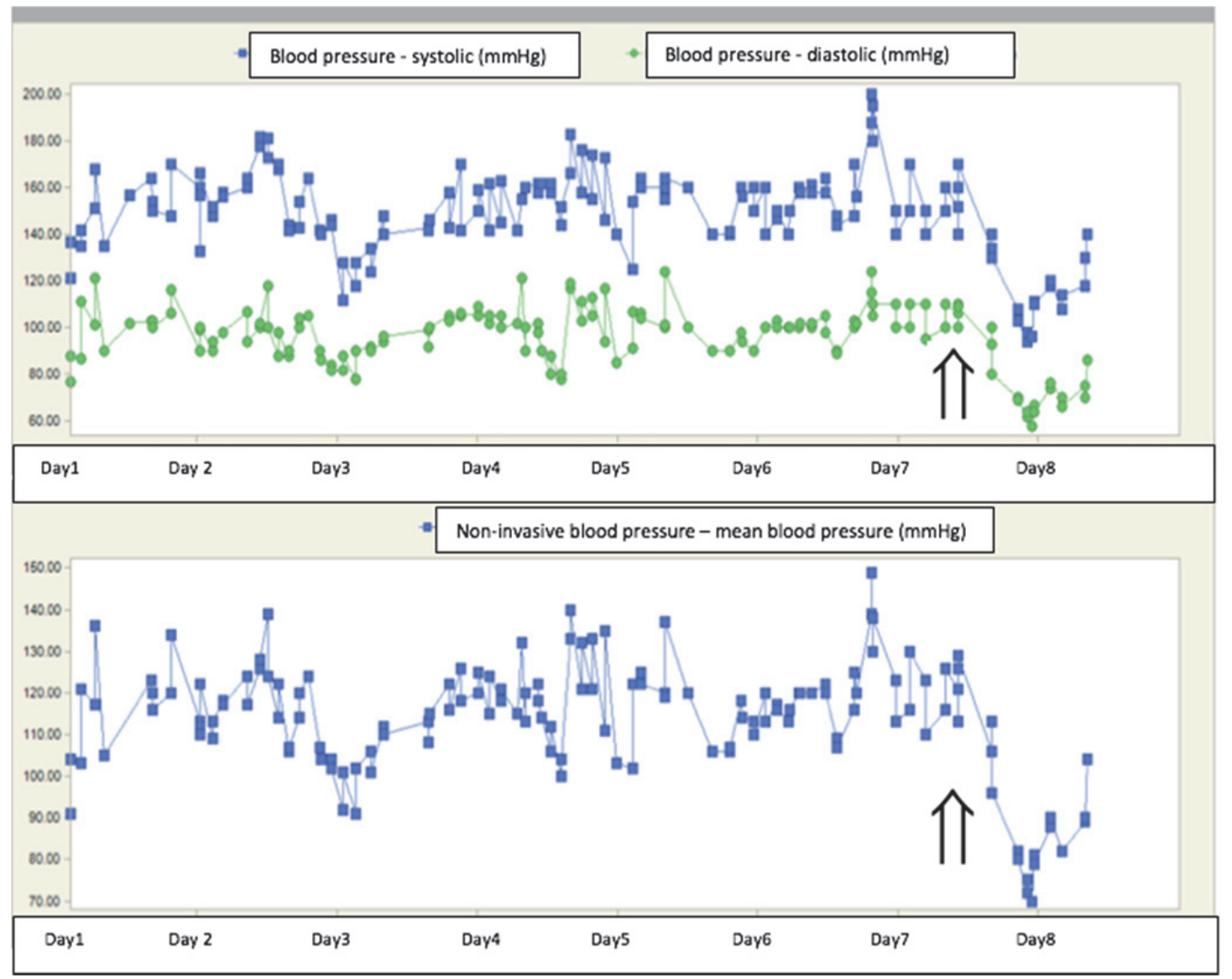

Figure 1. Blood pressure readings after placement of jejunostomy tube and transition to lisinopril 20 mg once daily (arrow pointing to the exact time of jejunostomy tube insertion).

Table 1. Drug level testing with oral only drug administration.

\begin{tabular}{|c|c|c|c|c|}
\hline Date of Administration & Drug & Date/Test & Results & Comments \\
\hline Day 1 to Day 6 & $\begin{array}{l}\text { Hydrochlorothiazide } 12.5 \\
\text { mg PO BID }\end{array}$ & $\begin{array}{l}\text { Day } 2 \text { Hydrochlorothiazide } \\
\text { urine test }\end{array}$ & Not detected & Using high performance liquid chromatography \\
\hline Day 1 to Day 5 & Labetalol 300 mg PO QID & Day 4 Plasma Labetalol & Not detected & \multirow{2}{*}{$\begin{array}{l}\text { Steady state plasma level following a daily regimen } \\
\text { should be } 36-183 \mathrm{ng} / \mathrm{mL} \text { for } 200 \mathrm{mg} \text { daily, } 84-205 \\
\mathrm{ng} / \mathrm{mL} \text { for } 400 \mathrm{mg} \text { daily. }\end{array}$} \\
\hline Day 6 to Day 13 & $\begin{array}{l}\text { Labetalol } 300 \text { mg TID Oral } \\
\text { suspension PO }\end{array}$ & Day 12 Plasma Labetalol & Not detected & \\
\hline
\end{tabular}

PO: orally / by mouth / oral administration; BID: Two times per day; TID: Three times per day; QID: Four times per day 


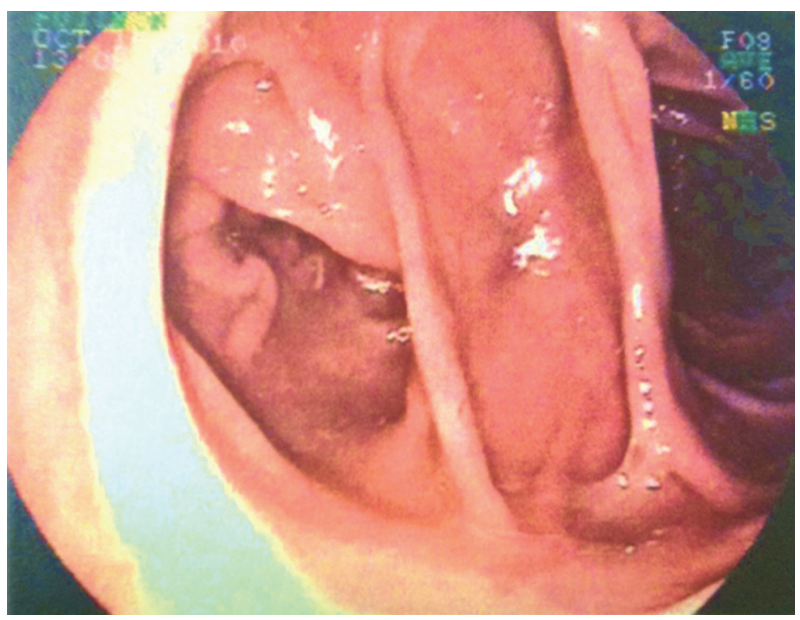

Figure 2. Note the esophagogastroduodenoscopy findings of retained saline in gastric pouch without passage into efferent limb.

gastrointestinal hydrochlorothiazide that was seen after intestinal shunt surgery ${ }^{[14]}$. Gastroenterology was subsequently consulted and diagnostic esophagogastroduodenoscopy (EGD) was performed on hospital day 10 disclosing retained water in a gastric pouch adjacent to the anastomotic site. Biopsy showed normal mucosa. The anatomical abnormality after bariatric surgery was believed to cause mechanical retention of medications (Fig. 2).

Upon confirming the diagnosis of a mechanical gastrointestinal complication causing altered pill pharmacokinetics, general surgery was consulted to discuss placement of jejunostomy tube (J-tube) to bypass the gastric pouch. The patient elected to proceed with J-tube placement, and was discharged on post-operative day 6 , with lisinopril monotherapy, 20 mg daily.

The oral exposure of metoprolol and other antihypertensive medications either immediaterelease or controlled-release formulations were not significantly different before compared with after RYGB procedure ${ }^{[15]}$. Although there was a tendency towards higher exposure following surgery, which could be explained by weight loss and a reduced pre-systemic biotransformation in the proximal gastrointestinal tract, our case findings do not coincide with literature which make our patient and this case a unique finding.

\section{Conclusion}

This case highlights the need for clinical attentiveness in assessing efficacy of oral medications following gastric bypass procedures. While there have been a sparse number of case reports documenting medications malabsorption following RYGB procedure, this is the first case that illustrates an anatomical alteration contributing to pill retention and change in medications' pharmacokinetics. This was confirmed by both drug concentration testing and endoscopic evaluation.

\section{Conflict of Interest}

The author has no conflict of interest.

\section{Disclosure}

The author did not receive any type of commercial support either in forms of compensation or financial for this study. The author has no financial interest in any of the products or devices, or drugs mentioned in this article.

\section{Ethical Approval}

Obtained.

\section{References}

[1] DeNicola E, Aburizaiza OS, Siddique A, Khwaja H, Carpenter DO. Obesity and public health in the Kingdom of Saudi Arabia. Rev Environ Health 2015; 30(3): 191-205.

[2] Angrisani L, Santonicola A, lovino P, Vitiello A, Zundel $N$, Buchwald $H$, Scopinaro N. Bariatric surgery and endoluminal procedures: IFSO Worldwide survey 2014. Obes Surg 2017; 27(9): 2279-2289.

[3] Santry HP, Gillen DL, Lauderdale DS. Trends in bariatric surgical procedures. JAMA 2005; 294(15): 1909-1917.

[4] Miller AD, Smith K. Medication and nutrient administration considerations after bariatric surgery. Am J Health Syst Pharm 2006;63(19): 1852-1857.

[5] Livingston EH. Complications of bariatric surgery. Surg Clin North Am 2005; 85(4): 853-868.

[6] Rouge N, Buri P, Dolker E. Drug absorption sites in the gastrointestinal tract and dosage forms for site-specific delivery. Int J Pharm 1996; 136(1-2): 117-139

[7] Chan LN. Drug therapy-related issues in patients who received bariatric surgery (Part I). Practical Gastroenterology 2010; 34(7): 26-32. 
[8] Flegal KM, Carroll MD, Kuczmarski RJ, Johnson CL. Overweight and obesity in the United States: prevalence and trends, 1960-1994. Int J Obes Relat Metab Disord 1998; 22(1): 39-47.

[9] Brolin RE. Metabolic deficiencies and supplements following bariatric operations. In: Obesity Surgery. 1st edn. Martin LF, ed. New York: McGraw-Hill, 2004. 275-99.

[10] Wills SM, Zekman R, Bestul D, Kuwajerwala N, Decker D. Tamoxifen malabsorption after Roux-en-Y gastric bypass surgery: case series and review of the literature. Pharmacotherapy 2010; 30(2): 217.

[11] Magee SR, Shih G, Hume A. Malabsorption of oral antibiotics in pregnancy after gastric bypass surgery. J Am Board Fam Med 2007; 20(3): 310-313.

[12] Sobieraj DM, Wang F, Kirton OC. Warfarin resistance after total gastrectomy and Roux-en-Y esophagojejunostomy. Pharmacotherapy 2008; 28(12): 1537-1541.

[13] Gesquiere I, Darwich AS, Van der Schueren B, de Hoon J, Lannoo M, Matthys C, Rostami A, Foulon V, Augustijns P. Drug disposition and modelling before and after gastric bypass: immediate and controlled-release metoprolol formulations. Br J Clin Pharmacol 2015; 80(5): 1021-1030.

[14] Backman L, Beerman B, Groschinsky-Grind M, Hallberg D. Malabsorption of hydrochlorothiazide following intestinal shunt surgery. Clin Pharmacokinet 1979; 4(1): 63-68.

[15] Darwich AS, Henderson K, Burgin A, Ward N, Whittam J, Ammori BJ, Ashcroft DM, Rostami-Hodjegan A. Trends in oral drug bioavailability following bariatric surgery: examining the variable extent of impact on exposure of different drug classes. Br J Clin Pharmacol 2012; 74(5): 774-787. 


\section{تحويل مسار المعدة وامتصاص أدوية علاج ارتفاع ضغط الدم}

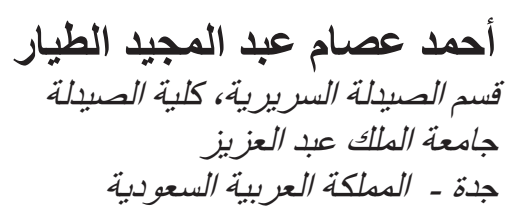

المستخلص. لا يعرف سوى القليل عن آثار تحويل مسار المعدة على امتصاص أدوية علاج ارتفاع ضغط الدم في حالة ما بعد الجر احة.

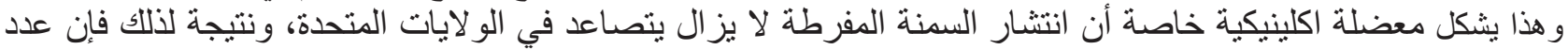

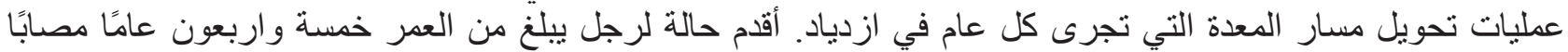

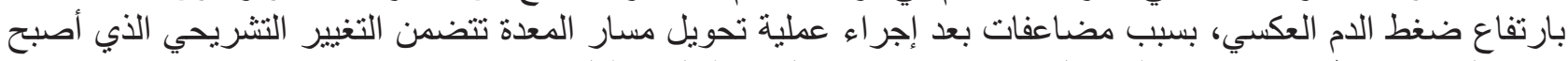
يؤدي الى الاحتفاظ بحبوب الادوية في المعدة وتغيير صفات العبات الحركية الدوائية لها.

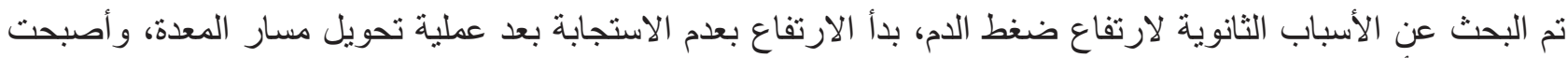

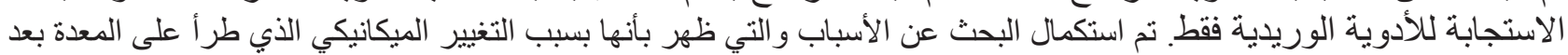

